\title{
Accessory Chromosomes and Their Meiotic Behaviour in Hybrids of Grain Sorghum and Johnson Grass
}

\author{
V. S. Raman, (Miss) K. Meenakshi and (Miss.) M. S. Thangam \\ Agricultural College and Research Institute, Coimbatore, India
}

Received August 22, 1974

The occurrence, cytological behaviour and genetical effects of accessory or B-chromosomes are now well known (Müntzing 1966, 1967). In a majority of plants with B-chromosomes, the number of accessories present at meiosis is the same as that found in the root tips. A few cases are also known where the accessories are eliminated from the somatic tissues and are only retained in the central parts of the plant. The first case of this kind was observed in a Para-Sorghum, S. purpureosericeum (Janaki Ammal 1940) and subsequently in Poa alpina (Müntzing 1946, 1948) and Panicum coloratum (Swaminathan and Joginder Nath 1956). Another Para-Sorghum, S. nitidum and a species of Eu-sorghum viz., S. halepense (Johnson grass) were also found to belong to this category (Raman and Krishnaswami 1960, Raman et al. 1964, 1965 and 1966). Diploid and tetraploid forms of $S$. nitidum $(2 \mathrm{n}=10$ and 20$)$ and $S$. halepense $(2 \mathrm{n}=20$ and 40$)$ have been found to be prevalent in natural populations (Garber 1950, Krishnaswamy and Raman 1953, 1953a, Krishnaswamy et al. 1956). Plants with acc. chromosomes are found only in diploid populations of the two species. The acc. chromosomes in S. nitidum $(2 \mathrm{n}=10+2$ B's) paired regularly and behaved normally at meiosis while those of $S$. halepense were inconstant $(2 n=20+4-6 \mathrm{~B}$ 's $)$ and aberrant in behaviour. Data presented below provide information on the cytological properties of the extra chromosomes present in the hybrids of S. subglabrescens and S. halepense.

\section{Material and methods}

The race of $S$. halepense possessing 4-6 extra chromosomes besides its normal complement of 20 was originally collected in the Nilgiris and subsequently maintained as a clone. Pollen of this plant was used in cross pollinations with the grain sorghum species, S. subglabrescens. Artificial crosses were effected after hand emasculation of the spikelets. For the study of meiosis, young panicles were fixed in Carnoy's fluid (3:4:1) and the smears of pollen mother cells stained in acetocarmine. The somatic chromosomes were also studied by Feulgen-acetocarmine squashes of root tips after pretreatment with 8 oxyquinoline for 3 hours and hydrolysis in $\mathrm{NHCl}$ for 25 minutes.

\section{Observations}

The availability of diploid hybrids between three different grain sorghums and the normal $S$. halepense facilitated a good comparison of these with the $F_{1}$ s pos- 
sessing acc. chromosomes. The divergence between the species of grain sorghum and $S$. halepense is significant both in morphology and in the development of isolation barriers. There is a distinct difference in the time of anthesis and natural habitat of the two. The percentage of seed set on spikelets of $S$. nervosum pollinated with pollen of $S$. halepense was 57.7 while in the reciprocal, it was 18.4. In crosses with $S$. subglabrescens, the percentage of seed set was 56.9 and the reciprocal gave a value of 14.3. Sixty four percent of spikelets of $S$. Roxburghii gave viable seeds on cross pollination, while pollen of this species on the emasculated spikelets of $S$. halepense could induce the development of only a few shrivelled seeds. The variation in the percentage of seed setting, and occurrence of inviable seeds on

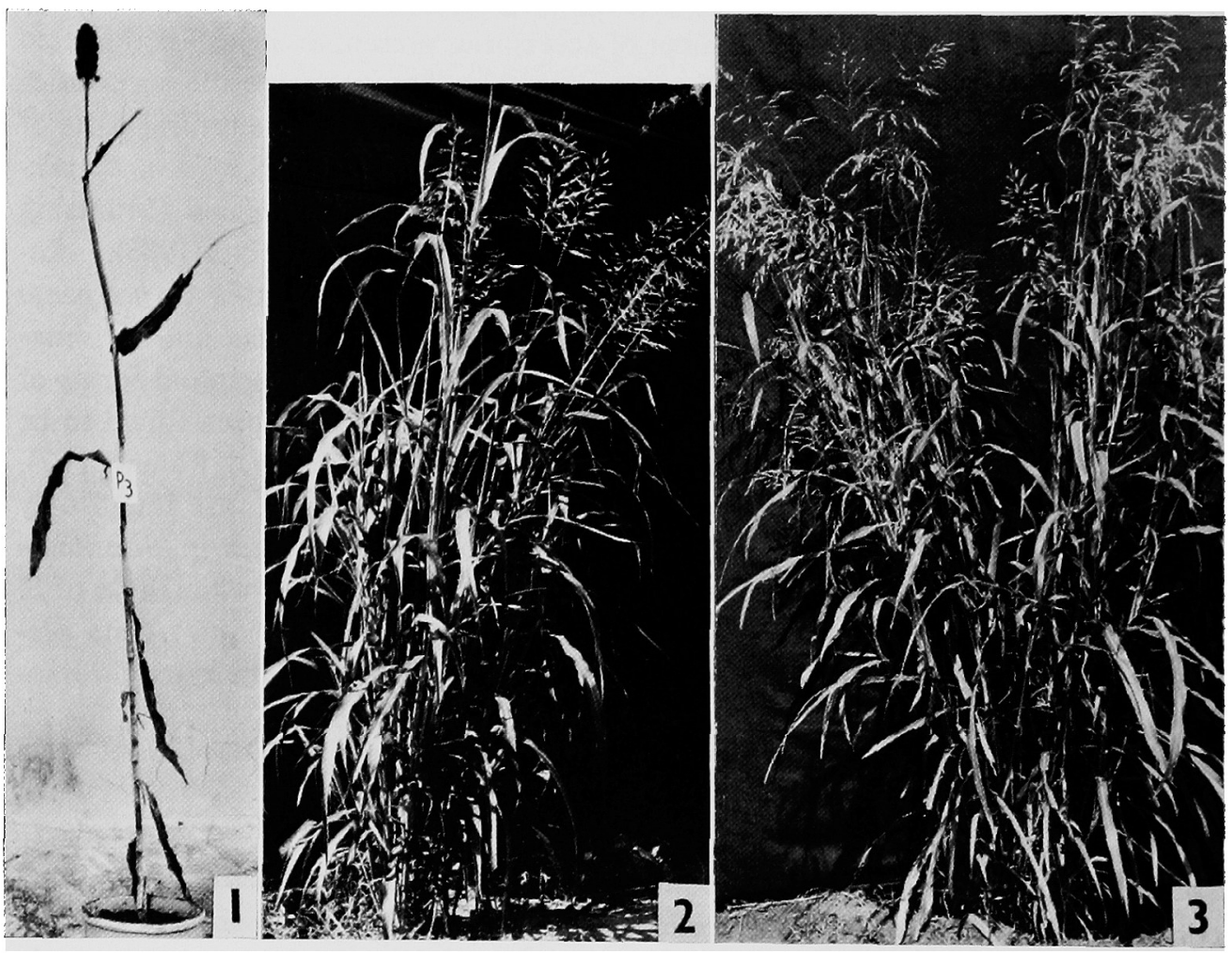

Figs. 1-3. Parents and hybrid. 1, S. subglabrescens $(2 \mathrm{n}=20) . \quad 2, \mathrm{~F}_{1}$ with 20 A plus $4-6 \mathrm{~B}-\mathrm{chro}-$ mosomes. 3, S. halepense $(2 n=20+4-6$ acc. chromosomes). Fig. $1.1 / 8$ 'nat' size. Fig. 2. 1/25 'nat' size and Fig. 3. 1/20 'nat' size.

cross pollination are indicative of the operation of incompletely developed cross incompatibility and failure of embryo development as isolation barriers.

The hybrids between the grain sorghums and $S$. halepense referred above have regular chromosome pairing and no evidence of gross structural differences in chromosome complements of the species was obtained from a study of the meiotic behaviour of the hybrids (Fig. 4). However, in spite of this regular meiosis, the $F_{1}$ s showed a reduction of 24 to 36 per cent in their pollen fertility compared with the parents. Seed sterility in the hybrids ranged from 42 to 48 per cent. The $F_{2}$ 
progenies showed predominance in the expression of characteristics of the wild species, their meiotic behaviour was similar to the hybrids and were also relatively

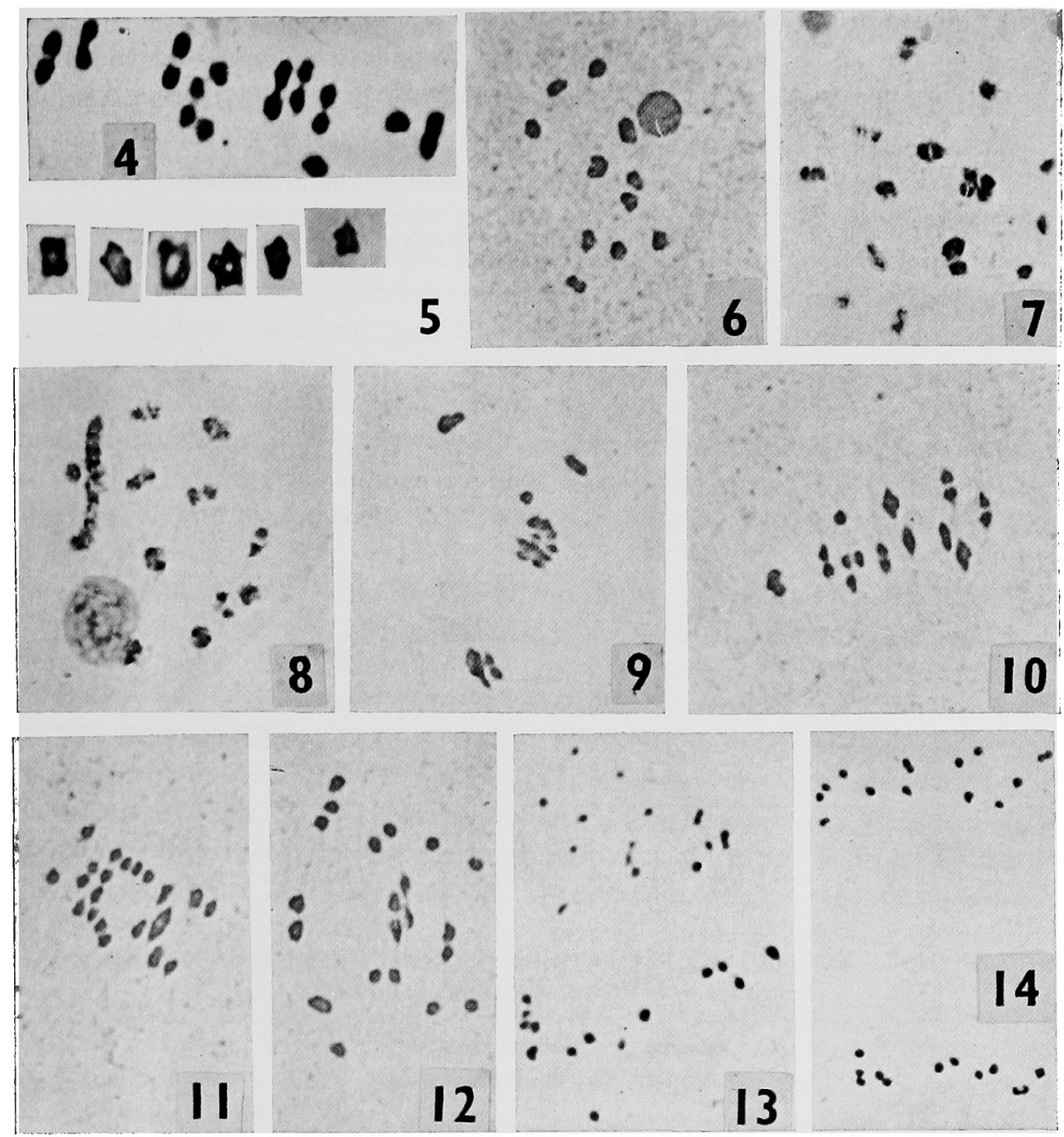

Figs. 4-14. Meiosis in hybrids possessing 4-6, 6-8 and 8-10 acc. chromosomes. 4, precocious disjunction of two bivalents at MI in hybrid between $S$. subglabrescens and $S$. halepense devoid of acc. chromosomes. 5, different configurations presented by the $\mathrm{B} 1$ and $\mathrm{B} 2$ bivalents. 6 , eleven bodies at diakinesis comprising $10 \mathrm{~A}$-bivalents plus a unit where the B1 and B2 pairs are held in close approximation. 7, fourteen bodies at diakinesis. One A-bivalent shows precocious disjunction. Of the five B-pairs, one is free and the rest approximate to form two groups. 8, a chain of eight acc. chromosomes and one free B-bivalent. 9, prometaphase. Note the approximation of one B-bivalent with two A-pairs. A second B-pair and a B-quadrivalent are also seen. 10, AI showing the sticky $\mathrm{B} 1$ and $\mathrm{B} 2$ bivalents away from the spindle and the precocious separation in some of the A-pairs. 11, AI. The B-quadrivalent disjoins as $2 / 2$ and three A-bivalents showing delayed disjunction. 12, AI. The B-quadrivalent migrating en bloc to one pole. 13, distribution of 14/16 at TI resulting from the non-disjunction of a B-bivalent in $F_{1}$ with 10 acc. chromosomes. 14, non disjunction in one of the three B-bivalents leading to 14/12 at TI in hybrid plant with 6 B-chromosomes. Figs. 4 and $5 \times 1600$. Figs. 13 and $14 \times 900$ and the rest $\times 1400$. 
fertile. No evidence of hybrid breakdown was apparent. The parental species appear to have genomic differentiation limited to genic and small structural changes (Krishnaswamy et al. 1956a, Ananthasayana 1964, Mahudeswaran and Raman 1972, Sethupathi Ramalingam and Raman 1974).

The clone of $S$. halepense with 4-6 acc. chromosomes resembled its normal counterpart in external morphology but differed in being more vigorous and pro-

Table 1. Disjunctional patterns of three B-bivalents at early $\mathrm{AI}$

\begin{tabular}{ccccc}
\hline \multirow{2}{*}{$\begin{array}{c}\text { Pattern } \\
\text { number }\end{array}$} & \multicolumn{3}{c}{$\begin{array}{c}\text { Manner of disjunction of accessory } \\
\text { bivalents }\end{array}$} & $\begin{array}{c}\text { No. of } \\
\text { PMCs }\end{array}$ \\
\cline { 2 - 4 } & $\mathrm{B}_{1}$ & $\mathrm{~B}_{2}$ & $\mathrm{~B}_{3}$ & \\
\hline 1 & $1 / 1$ & $1 / 1$ & $1 / 1$ & 5 \\
2 & $1 / 1$ & $1 / 1$ & $2 / 0$ & 11 \\
3 & $1 / 1$ & $0 / 2$ & $1 / 1$ & 7 \\
4 & $1 / 1$ & $1 / 1$ & Eliminated & 6 \\
5 & $2 / 0$ & $2 / 0$ & $1 / 1$ & 13 \\
6 & $2 / 0$ & $2 / 0$ & Eliminated & 12 \\
7 & $2 / 0$ & $1 / 1$ & - do- & 9 \\
8 & $2 / 0$ & $1 / 1$ & $1 / 1$ & 11 \\
9 & $2 / 0$ & $2 / 0$ & $2 / 0$ & 6 \\
\hline
\end{tabular}

Table 2. Distribution of B-chromosomes at T1

\begin{tabular}{|c|c|c|c|c|c|c|c|c|c|c|c|c|c|c|}
\hline \multicolumn{4}{|c|}{$\begin{array}{l}\text { Cells without } \\
\text { laggards }\end{array}$} & \multicolumn{10}{|c|}{ Cells with lagging chromosomes } & \multirow{2}{*}{$\begin{array}{l}\text { No. of } \\
\text { PMCs }\end{array}$} \\
\hline $0 / 6$ & $1 / 5$ & $2 / 4$ & $3 / 3$ & $0 / 2$ & $0 / 3$ & $0 / 4$ & $0 / 5$ & $1 / 1$ & $1 / 2$ & $1 / 3$ & $1 / 4$ & $2 / 2$ & $2 / 2$ & \\
\hline 2 & 3 & 3 & 4 & 4 & 2 & 4 & 4 & 4 & 3 & 4 & 3 & 4 & 4 & 48 \\
\hline
\end{tabular}

Table 3. Variation in size of three classes of pollen grains and their frequencies in hybrids with $4-6$ acc. chromosomes $(\times 3.1$ for $\mu$ ).

\begin{tabular}{|c|c|c|c|c|c|c|c|}
\hline \multirow{2}{*}{ Category } & \multicolumn{4}{|c|}{$\begin{array}{l}\text { Diameter of pollen grains } \\
\text { (in oc. mic. divisions) }\end{array}$} & \multirow{2}{*}{ Mean } & \multirow{2}{*}{ S.E. } & \multirow{2}{*}{$\begin{array}{l}\mathrm{CV} \\
(\%)\end{array}$} \\
\hline & $9-11$ & $12-14$ & $15-17$ & $18-20$ & & & \\
\hline A. Stainable (fertile) & - & 116 & 80 & 4 & 14.32 & 0.095 & 9.35 \\
\hline $\begin{array}{l}\text { B. Non-stainable } \\
\text { (sterile) }\end{array}$ & 164 & 34 & 2 & - & 10.57 & 0.064 & 8.51 \\
\hline C. Germinable & - & 128 & 65 & 7 & 14.19 & 0.101 & 10.07 \\
\hline
\end{tabular}

ducing about 60 per cent of ill-filled and deformed pollen grains. Seed set under open pollination was reduced to nearly one third of that realised from panicles of the plant devoid of the acc. chromosomes.

Twelve hybrids were derived from cross pollination of the spikelets of $S$. subglarescens with pollen from the B-race of $S$. halepense, the percentage of success being 48 per cent (Figs. 1-3). Six of them showed only 4 accessories, two had 4-6, 
in two others the B's ranged from 6-8 and in one from 8-10. In the last $F_{1}$, the PMCs carried 6, 8 and $10 \mathrm{~B}$ chromosomes. The number of chromosomes in the root tip cells determined by the rapid squash technique was only 20 in all the hybrids. The $F_{1} s$ carrying 8 and more accessories in addition to the normal complement of 20, were found to be less vigorous and exhibited a reduction in vegetative and floral organs. Compared to the male parent, a progressive reduction in fertility accompanied an increase in the number of B-chromosomes in the hybrids.

Meiosis: The behaviour of the B-chromosomes in the hybrid with 4-6 accessories, described below, is similar to that observed in the meiosis of the male parent. In the hybrid, the number of bodies noticed at diakinesis was not constant. Two A-bivalents formed the nucleolar chromosomes. The 6 accessories presented themselves as three individual paris in less than 10 per cent of PMCs. In a majority of cases, they were seen as two extra bodies, one being constituted of two B-bivalents in close approximation while the other was a free bivalent (Fig. 5). The former is referred in the text as the $B_{1}$ and $B_{2}$ bivalents and the latter as the $B_{3}$ pair. The $\mathbf{B}_{3}$ bivalent was absent in about 20 per cent of cells exhibiting eleven bodies (Fig. 6) and in such cells the $\mathbf{B}_{1}$ and $\mathbf{B}_{2}$ pairs gave distributions of $2 / 2,0 / 2$ and $0 / 4$ at $\mathrm{AI}$.

With regard to stainability, the $\mathbf{B}_{3}$ was less deeply stained than the A-bivalents. The intensity of staining of the A-bivalents and that of the $B_{1}$ and $B_{2}$ pairs was, however, the same. The differential staining was more apparent, in the $\mathrm{A}$ and B-univalents, the stainability of the latter being somewhat less. Compact MI plates are formed in a majority of cases. Secondary association is pronounced and the B-pairs are seen to approximate themselves with the A-bivalents (Fig. 9). The $\mathrm{A}$ and $\mathrm{B}$ bivalents exhibited precocious and delayed disjunction. The stickiness of the $\mathbf{B}_{1}$ and $\mathbf{B}_{2}$ pairs to constitute the multivalent structure was evident. Spindle abnormalities are not much pronounced. The accessories also take up positions away from the spindle and get eliminated or revealed a tendency for non-disjunction to be incorporated in the daughter nuclei (Figs. 10-12 and 13-14).

The disjunctional behaviour of the three B-bivalents at early AI is presented in Table 1. It may be noted that normal disjunction and en bloc movement is characteristic of all the pairs while the $\mathbf{B}_{3}$ gets eliminated in about thirty four per cent of the cells analysed. Most AI figures showed whole and dividing univalents. Seventy five per cent of the cells showed 1-4 laggards at TI (Table 2). In 25 per cent of the cells they get incorporated in the daughter nuclei, the distribution being $0 / 6,1 / 5,2 / 4$ and $3 / 3$ and these could be matched with the disjunctional behaviour of the bivalents, indicated against pattern numbers $9,5,8$ and 1 respectively. The frequencies of cells with the four different distributions at TI were considerably reduced compared to their corresponding values at early AI. That the initial disjunctional behaviour of the accessory pairs is no indication of their ultimate distributions is evident from the high frequency of cells with laggards. Lagging of the half B-univalents was noticed at AII and bridges at this stage were exceptional. Where four telophase groups are organised in a regular way, fusion of adjascent nuclei was noticed occasionally. Apparently good pollen was ascertained by counting eight hundred and five grains. Fifty eight percent of well-filled pollen grains 
were produced and their size ranged from 37.2 to $58.9 \mu$. Pollen and seed fertility in hybrids of similar parentage but lacking the acc. chromosomes are 76 and 56 per cent respectively. The variation in size of fertile and sterile pollen and that of the microspores germinated in vivo is presented in Table 3 . The differences in frequencies under the size classes of the stainable pollen and of microspores germinated on the stigma are not marked. The sterile grains are smaller, eighty two per cent of these conformed to the range in size from 28 to $34 \mu$ which is much lower than the minimum level of expression of the fertile grains. The difference between the mean size of pollen grains of the two categories $A$ and $C$ is not significant as revealed from the ' $t$ ' test, while the average size of microspores of the category $\mathrm{B}$ was found to be significantly different from the corresponding values of $\mathrm{A}$ and $\mathrm{C}$ at probability 0.01 level.

Hybrids with 4 B's always exhibited two independent bivalents. In $F_{1} s$ with 6-8 accessories, the $B_{1}, B_{2}$ and $B_{3}$ pairs were present in addition to either one of the former two. The most frequent configuration was an association of three pairs plus a free bivalent. Occasionally, a quadrivalent and two independent bivalents were also noticed. Either an association of four pairs and a free bivalent or two groups consisting of two pairs each plus a free pair was characteristic of the $F_{1}$ with 8-10 $\mathrm{B}$ chromosomes, indicating thereby the duplication of the $\mathrm{B}_{1}$ and $\mathrm{B}_{2}$ bivalents (Figs. 7 and 8). Pollen mother cells showing 6 and 8 chromosomes in these hybrids probably lacked the $B_{3}$ pair as a result of elimination during premeiotic mitosis and the frequency of cells with the minimum number of accessories was around 20 per cent. In the last hybrid, 6-10 acc. chromosomes were present in the same anther. Twenty seven per cent of the PMCs revealed 6 acc. chromosomes and twenty per cent carried 10 such chromosomes; eight B-chromosomes were found in 53 per cent of cells. The ten accessories either formed a long chain of eight plus a free pair or presented two configurations each consisting of two bivalents in approximation and leaving an independent pair. Cells with 6 and 8 acc. chromosomes probably do not exhibit the $\mathrm{B}_{3}$ pair and in the former case, the $B_{1}$ and $B_{2}$ bivalents occur with an additional unit of either one of them. Degeneration of PMCs was noticed in hybrids with 8 and 10 B-chromosomes. Gametes resulting if at all, from PMCs devoid of the $B_{3}$ are probably inviable as evidenced from the non-recovery of hybrids carrying the $B_{1}$ and $B_{2}$ pairs alone. The $B_{3}$ therefore, appears to be a companion pair. The quantity of apparently good pollen in the hybrids with $6-8$ and $8-10$ accessories was 42 and 28 per cent respectively and in the $F_{1}$ with 6-10 chromosomes it was 16 per cent. A higher percentage of seed sterility than that of pollen occurred in these hybrids. The seeds were rather small and shrivelled.

\section{Discussion}

Darlington and Thomas (1941) reported three kinds of B-chromosomes in $S$. purpureosericeum, viz., large standard chromosome (M), large iso-chromosome (L) and short chromosome (S). Again, Garber (1950) observed that of these, two (M and $\mathrm{S}$ ) were present in the sub-species decanense and typicum. The two accessories in $S$. nitidum paired with each other and because of their equal size, they were 
classified under the standard type (Raman and Krishnaswami 1960). The supernumerary chromosomes of $S$. halepense can also be grouped under the standard category since they are seen only as pairs and are not appreciably larger in size than the A-chromosomes. Further, the B's exhibited the property of stickiness and variable in their number in the reproductive cells. Numerical increase is a phenomenon specific for the acc. chromosomes in grasses and in this respect, the B-race of $S$. halepense is no exception. The chimaerical PMCs with regard to the minimum and maximum number of accessories were also observed in only half the number of hybrids tested. In such cells with lower number of B's the $\mathbf{B}_{3}$ pair seemed to be absent. The three pairs in 'normal' cells exhibited independence in segregation, and their co-existence in gametes appeared to be necessary as evident by their presence in the hybrids. The nature of approximation of the $\mathbf{B}_{1}$ and $\mathbf{B}_{2}$ pairs in the 8 and 10 chromosome $F_{1}$ s indicated the partial homology of the chromosomes of the two sets and this property, probably facilitated the 'stickiness' exhibited by them. The acc. bivalents of $S$. halepense, therefore, seem to be of three kinds of which two show partial relationship. The sterility appears to result mainly from the behaviour of accessories during meiosis and a linear relationship can be found between the level of sterility and the number of acc. chromosomes present in the hybrids. In view of the limited number of progeny obtained, it is unsafe to draw definite conclusions regarding the relative competitive ability of male gametes of the B parent in fertilisation. An evaluation of the frequency of B-chromosomes in large hybrid populations and selfed progenies of the B-race of $S$. halepense should provide more reliable estimates on the rate of transmission of the accessories from the male and female sides. A survey on the distribution of acc. chromosomes in natural populations of the species is also called for. The resemblances and differences between the B-chromosomes of the Para and Eu-sorghums both in morphology and behaviour in reproduction are of phylogenetic importance. Infecting the diploid grain and grass sorghums with the acc. chromosomes of $S$. halepense is a field of study, the findings of which will supply interesting and useful information from the fundamental and applied cytogenetic points of view.

\section{Summary}

Crosses between the grain sorghum species, $S$. subglabrescens $(2 \mathrm{n}=20)$ and a diploid race of $S$. halepense $\left(2 n=20+4-6\right.$ B's) yielded $F_{1}$ s exhibiting constant and oscillating number of accessories only in the PMCs. Six hybrids showed only 4, two $F_{1} s$ had 4-6, in two others the accessories ranged from 6-8 and in one from $8-10$. In the last hybrid, 6,8 and $10 \mathrm{~B}$ chromosomes could be found in PMCs of an anther.

The size of the accessories was not appreciably large compared to the A-chromosomes and the former occurred only in pairs. They segregated independently of each other and exhibited normal separation, delayed disjunction, elimination and en-bloc movement at AI. Lagging of the B-chromosomes also occurred at AI and AII leading to their expulsion. Three $B$-pairs, $B_{1}, B_{2}$ and $B_{3}$ could be recognised of which the former two presented configurations involving four or more chromosomes depending on their numerical strength. The presence of the $B_{3}$ in all hybrids 
emphasises the importance of coexistence of accessories in gametes of the male parent for successful cross pollinations.

\section{References}

Ananthasayana, K. 1964. Studies on some interspecific hybrids in the genus Sorghum. M. Sc. (Ag) Dissertation, Madras Univ. Unpubl.

Darlington, C. D. and Thomas, P. T. 1941. Morbid mitosis and the activity of the inert chromosomes in Sorghum. Proc. roy. Soc. 130 (B): 127-150.

Garber, E. D. 1950. Cytotaxonomic studies in the genus Sorghum. Univ. Calif. Publ. Bot. 23: 283-362.

Janaki Ammal, E. K. 1940. Chromosome diminution in a plant. Nature, Lond. 146: 839-840.

Krishnaswamy, N. and Raman, V. S. 1953. A not on Sorghum nitidum. Madras agric. J. 40:115.

- and - 1953 a. Sorghum halepense and its relationship to the cultivated grain sorghums. Proc. 3rd Sci. Wkrs'. Conf. Madras Agric. Dept. S. No. 5/1954: 58-63. Pub: Supdt. Govt. Press. Madras.

-, - and Chandrasekharan, P. 1956. Studies on Sorghum nitidum. Curr. Sci. 25: 64-65.

-, - and - 1956 a. An interspecific hybrid of grain sorghum and Johnson grass. ibid. 25: 195-197.

Mahudeswaran, K. and Raman, V. S. 1972. The breeding behaviour of an interspecific hybrid in Sorghum. Sorghum Newsletter. 15: 34-38.

Müntzing, A. 1946. Different chromosome numbers in root tips and pollen mother cells in a sexual strain of Poa alpina. Hereditas 32: 127-129.

- 1948. Accessory chromosomes in Poa alpina. Heredity 2: 49-61.

- 1966. Accessory chromosomes. Bull. Bot. Soc. Bengal. 20: 1-15.

- 1967. Some main results from investigations of accessory chromosomes. Hereditas 57: 432-438.

Raman, V. S. and Krishnaswami, D. 1960. Accessory chromosomes in Sorghum nitidum. J. Indian bot. Soc. 39: $278-280$.

-, Meenakshi, K., Thangam, M. S. and Sivagnanam, L. 1964. The cytological behaviour of Bchromosomes in Sorghum halepense. Abst. in Madras agric. J. 51: 72-73 and full article in J. Indian bot. Soc. 45: 82-84. 1966.

-, - and Thangam, M. S. 1965. Paternal transmission of accessory chromosomes in a species of Eu-Sorghum. Sci. and Cult. 31: 150-151.

Sethupathi Ramalingam, R. and Raman, V. S. 1974. Cytogenetics of interspecific hybrids in Sorghum. Cytologia 39: 265-274.

Swaminathan, M.S. and Joginder Nath. 1956. B-chromosomes in Panicum coloratum. Curr. Sci. 25: 123-124. 